Article

\title{
Simultaneous Dual-Mode Emission and Tunable Multicolor in the Time Domain from Lanthanide-Doped Core-Shell Microcrystals
}

\author{
Dandan Ju ${ }^{1,2}$, Feng Song ${ }^{1,2, *}$, Adnan Khan ${ }^{1,2}$, Feifei Song ${ }^{1}$, Aihua Zhou ${ }^{1,2}$, Xiaoli Gao ${ }^{1,2}$, \\ Huimin $\mathrm{Hu}^{1,2}$, Xu Sang ${ }^{1,2}$ and Victor Zadkov ${ }^{3}$ \\ 1 School of Physics \& The Key Laboratory of Weak Light Nonlinear Photonics, Ministry of Education, \\ Nankai University, Tianjin 300071, China; judandan@mail.nankai.edu.cn (D.J.); \\ adnanphyzx@mail.nankai.edu.cn (A.K.); songff@mail.nankai.edu.cn (F.S.); \\ zhouihua@mail.nankai.edu.cn (A.Z.); 1120180066@mail.nankai.edu.cn (X.G.); \\ 2120170177@mail.nankai.edu.cn (H.H.); 2120180202@mail.nankai.edu.cn (X.S.) \\ 2 Collaborative Innovation Center of Extreme Optics, Shanxi University, Taiyuan 030006, Shanxi, China \\ 3 The Institute of Spectroscopy of the Russian Academy of Sciences, Moscow 142190, Russia; \\ zadkov@isan.troitsk.ru \\ * Correspondence: fsong@nankai.edu.cn; Tel.: +86-022-23502572
}

Received: 21 November 2018; Accepted: 6 December 2018; Published: 7 December 2018

\begin{abstract}
The dual-mode emission and multicolor outputs in the time domain from core-shell microcrystals are presented. The core-shell microcrystals, with $\mathrm{NaYF}_{4}: \mathrm{Yb} / \mathrm{Er}$ as the core and $\mathrm{NaYF}_{4}: \mathrm{Ce} / \mathrm{Tb} / \mathrm{Eu}$ as the shell, were successfully fabricated by employing the hydrothermal method, which confines the activator ions into a separate region and minimizes the effect of surface quenching. The material is capable of both upconversion and downshifting emission, and their multicolor outputs in response to $980 \mathrm{~nm}$ near-infrared (NIR) excitation laser and $252 \mathrm{~nm}$, and $395 \mathrm{~nm}$ ultraviolet (UV) excitation light have been investigated. Furthermore, the tunable color emissions by controlling the $\mathrm{Tb}^{3+}-\mathrm{Eu}^{3+}$ ratio in shells and the energy transfer of $\mathrm{Ce}^{3+} \rightarrow \mathrm{Tb}^{3+} \rightarrow \mathrm{Eu}^{3+}$ were discussed in details. In addition, color tuning of core-shell-structured microrods from green to red region in the time domain could be obtained by setting suitable delay time. Due to downshifting multicolor outputs (time-resolved and pump-wavelength-induced downshifting) coupled with the upconversion mode, the core-shell microrods can be potentially applied to displays and high-level security.
\end{abstract}

Keywords: $\mathrm{NaYF}_{4}: \mathrm{Yb} / \mathrm{Er} @ \mathrm{NaYF}_{4}: \mathrm{Ce} / \mathrm{Tb} / \mathrm{Eu}$ microrods; dual-mode emission; time-resolved emission spectra; multicolor emission

\section{Introduction}

Lanthanide $\left(\mathrm{Ln}^{3+}\right)$-doped luminescent materials with various compositions and properties have been well studied for the last few decades. Compared with traditional luminescent materials, such as quantum dots (QDs) and organic dyes, the lanthanide-doped nano- and micro-crystals show more superior optical features including narrow bands widths, stable energy levels, low toxicity and long lifetime [1,2]. In addition, these materials have attracted a great deal of attention owing to their magnetic and thermal properties. These properties lead to widespread applications in various areas, such as volumetric display [3,4], solar cell [5], optical data storage [3,6,7], photothermal therapy [8,9], temperature sensing [10], laser [11,12], bioimaging [13,14] and anti-counterfeiting $[2,15,16]$. $\mathrm{Ln}^{3+}$-doped materials with tunable emission colors as security inks have been one of most commonly utilized methods for high-level anti-fake due to its difficult duplication and tunable luminescence properties $[15,17,18]$. The emission colors from near-ultraviolet (UV) to 
NIR region have been realized in $\mathrm{Ln}^{3+}$-doped particles by adjusting the types and concentrations of emitters and sensitizers [19-21]. For example, the $\mathrm{Eu}^{3+}$ ions could emit visible color under UV illumination, which is applied to the anti-counterfeiting purpose in banks [22]. This approach of photoluminescence process is downshifting (DS). The well-known upconversion (UC) rare earth pairs, which can produce intense green, red, violet emissions using $980 \mathrm{~nm}$ excitation, are $\mathrm{Yb}^{3+} / \mathrm{Tm}^{3+}\left(\mathrm{Er}^{3+}\right.$, $\left.\mathrm{Ho}^{3+}\right)$ systems $[5,13,15,22,23]$. The dual-mode emission with different emission colors in a single microcrystal could provide an opportunity for higher-level anti-counterfeiting. Moreover, in order to decrease the affection of unnecessary luminescence quenching, these UC and DS $\mathrm{Ln}^{3+}$ ions dopants are usually doped into the core and shell layer, respectively. This design disturbs the interaction between these lanthanide ions, and is beneficial to overcome the luminescence quenching $[1,13,22]$.

Among the different inorganic host matrices like oxides, fluorides, and chlorides, the inorganic fluorides are chosen as efficient host materials for both UC and DS luminescence to achieve multicolor tuning. The selection is attributed to their low phonon energy and high stability [3,22-24]. Hexagonal-phase $\mathrm{NaYF}_{4}$ is not only considered as excellent UC host materials, but also offers efficient DS emission of $\mathrm{Ln}^{3+}$ ions such as $\mathrm{Tb}^{3+}$ and $\mathrm{Eu}^{3+}$, hence generating bright green and red DS emission in the visible region $[25,26]$. Thus, recently, the $\mathrm{Tb}^{3+}$ and $\mathrm{Eu}^{3+}$ co-doping in host has aroused many researchers' interest due to tunable DS emission colors [19,27-29]. However, in these literatures, quite little attention has been paid to $\mathrm{Tb}$-Eu co-doped core-shell-structured nanoparticles for dual-mode emission. Furthermore, only core-shell nanoparticles have been investigated to realize tunable emission colors, while studies on hetro- and homogenous microrods structures are still indispensable [3,30,31].

Herein, we propose a strategy to synthesize uniform $\beta-\mathrm{NaYF}_{4}$ microrods that are composed of $\mathrm{NaYF}_{4}: \mathrm{Yb} / \mathrm{Er}(\mathrm{Tm})$ core and $\mathrm{NaYF}_{4}: \mathrm{Ce} / \mathrm{Tb} / \mathrm{Eu}$ shell for achieving dual-mode anti-counterfeiting. These dual-mode core-shell microrods can generate intense multicolor (green, yellow, orange and red) depending on the pump wavelengths (NIR or UV light), the concentration of dopants in shells and detection delay time. Furthermore, due to their microscale dimensions, the materials not only retain higher luminescence efficiency but also have a less complicated process, and lower costs due to lack of filter and outmost layers. Therefore, these materials present adjustable color that could be used as multicolor labels to improve the multimode anti-fake level.

\section{Materials and Methods}

\subsection{Materials}

$\mathrm{Y}\left(\mathrm{NO}_{3}\right)_{3} \cdot 6 \mathrm{H}_{2} \mathrm{O}(99.99 \%), \mathrm{Yb}\left(\mathrm{NO}_{3}\right)_{3} \cdot 5 \mathrm{H}_{2} \mathrm{O}(99.99 \%), \mathrm{Er}\left(\mathrm{NO}_{3}\right)_{3} \cdot 6 \mathrm{H}_{2} \mathrm{O}(99.99 \%), \mathrm{Tb}\left(\mathrm{NO}_{3}\right)_{3} \cdot 6 \mathrm{H}_{2} \mathrm{O}$ (99.99\%), $\mathrm{Eu}\left(\mathrm{NO}_{3}\right)_{3} \cdot 6 \mathrm{H}_{2} \mathrm{O}(99.99 \%), \mathrm{Ce}\left(\mathrm{NO}_{3}\right)_{3} \cdot 6 \mathrm{H}_{2} \mathrm{O}(99.99 \%), \mathrm{NaOH}(>98 \%)$ were supplied by the HWRK Chemical Co. Ltd., Beijing, China. $\mathrm{NH}_{4} \mathrm{~F}$ was supplied by Damao Chemical Reagent Factory, Tianjin, China. NaF was supplied by Jiangtian Chemical Technology Co. Ltd., Tianjin, China. Ethylenediaminetetraacetic acid disodium salt (EDTA-2Na) were supplied by Aladdin Chemical Reagent Co. Ltd., Shanghai, China. Oleic acid (OA), and ethanol were supplied by SanJiang Chemical Technology Co. Ltd., Tianjin, China. All of the chemicals used in this study were of analytical grade and used in the original condition without any further purification.

\subsection{Preparation of $\beta-\mathrm{NaYF}_{4}: \mathrm{Yb} /$ Er Microrods}

The $\beta-\mathrm{NaYF}_{4}: \mathrm{Yb} / \mathrm{Er}$ microrods were synthesized following a previous approach in the literature [17].

\subsection{Preparation of Seeding Microrods}

All the as-prepared $\beta-\mathrm{NaYF}_{4}: \mathrm{Yb} / \mathrm{Er}$ microrods could be used as seeds after surface treatment. The seeds were prepared following a previous approach in the literature $[18,32]$. 


\subsection{Sequential of Core-Shell-Structured Microrods}

The core-shell-structured microrods were synthesized with EDTA-2Na as a chelating agent. The EDTA-2Na $(4.70 \mathrm{~mL})$ solution was mixed with the rare earth aqueous solution $\mathrm{Ln}\left(\mathrm{NO}_{3}\right)_{3}(1.875 \mathrm{~mL}$, $0.2 \mathrm{M} ; \mathrm{Ln}=\mathrm{Ce}^{3+}, \mathrm{Tb}^{3+}$, and $\left.\mathrm{Eu}^{3+}\right)$. After vigorously stirring, the $\mathrm{NH}_{4} \mathrm{~F}(5 \mathrm{~mL}, 2 \mathrm{M})$, and $\mathrm{NaF}(10 \mathrm{~mL}$, $0.5 \mathrm{M})$ were added. Then, the $\mathrm{HCl}(1.875 \mathrm{~mL}, 2 \mathrm{M}), \mathrm{HNO}_{3}(1.875 \mathrm{~mL}, 15 \mathrm{wt} \%)$ and the seed crystals $(0.094 \mathrm{~g})$ were mixed. The resulting mixture was stirred for $40 \mathrm{~min}$ and then transferred into a $50 \mathrm{~mL}$ Teflon-lined autoclave for heating at $220^{\circ} \mathrm{C}$ for $700 \mathrm{~min}$. The samples were spectively centrifuged and washed with deionized (DI) water and ethanol 3 times.

\subsection{Characterization}

$X$-ray diffraction (XRD) patterns in the $2 \theta$ ranging from 10 to 80 were measured by the $\mathrm{D} /$ max-2500 X-ray diffractometer equipped with graphite-monochromatized $\mathrm{Cu} K \alpha$ radiation $(\lambda=1.54056 \AA)$ (Riagaku Co. Ltd., Tokyo, Japan). The morphologies of the products were recorded by an scanning electron microscopy (SEM) on ZEISS MERLIN Compact (Carl Zeiss, Oberkochen, Germany) operating at $3 \mathrm{kV}$. Energy dispersive X-ray spectrometer (EDS) and scanning transmission electron microscopy (STEM) images were performed on the Tecnai G2 F30 transmission electron microscope (FEI, Hillsborough, OR, USA). The UC and DS emission spectra of samples were recorded on a Horiba Fluorolog-3 luminescence spectrometer (Horiba, Edison, NJ, USA) using a $980 \mathrm{~nm}$ continuous wave laser. The DS luminescence delay time and time-resolved emission spectra (TRES) were recorded on an Edinburgh FSP-920 fluorescence spectrometer (Edinburgh Instruments, Livingston, Scotland, UK) with the excitation of pulsed Xeon lamp at $252 \mathrm{~nm}$ and $395 \mathrm{~nm}$. All the measurements were performed at room temperature.

\section{Results and Discussion}

The lanthanide-doped $\beta-\mathrm{NaYF}_{4}$ core-shell microcrystals that are composed of $\mathrm{NaYF}_{4}: \mathrm{Yb} / \mathrm{Er}$ as the core and $\mathrm{NaYF}_{4}: \mathrm{Ce} / \mathrm{Tb} / \mathrm{Eu}$ as the shell for dual-mode emission (UC and DS) were fabricated by hydrothermal reaction. The $\mathrm{NaYF}_{4}: \mathrm{Yb} / \mathrm{Er}$ core microrods served as seed microrods after acid cleaning for the shell growth, resulting in the formation of core-shell $\mathrm{NaYF}_{4}: \mathrm{Yb} / \mathrm{Er} @ \mathrm{NaYF}_{4}: \mathrm{Ce} / \mathrm{Tb} / \mathrm{Eu}$ microcrystals. The morphologies of materials are displayed by SEM images (Figure 1a-d). Figure 1a shows that the image of seed crystals, with a length and a diameter of about 1.20 and $0.21 \mu \mathrm{m}$, respectively. Figure $1 \mathrm{~b}-\mathrm{d}$ indicate the SEM images of $\mathrm{NaYF}_{4}: \mathrm{Yb} / \mathrm{Er} @ \mathrm{NaYF}_{4}: \mathrm{Ce} / \mathrm{Tb}_{0.1}$, $\mathrm{NaYF}_{4}: \mathrm{Yb} / \mathrm{Er} @ \mathrm{NaYF}_{4}: \mathrm{Ce} / \mathrm{Tb}_{0.1} / \mathrm{Eu}_{0.05}$, and $\mathrm{NaYF}_{4}: \mathrm{Yb} / \mathrm{Er} @ \mathrm{NaYF}_{4}: \mathrm{Ce} / \mathrm{Eu}_{0.1}$ microrods, respectively. The size distribution analysis of all samples are displayed in Figure S1 (Supplementary Materials), indicating the $\mathrm{NaYF}_{4}: \mathrm{Ce} / \mathrm{Tb} / \mathrm{Eu}$ active shells are grown onto the surface of $\mathrm{NaYF}_{4}: \mathrm{Yb} / \mathrm{Er}$ core microrods. Furthermore, the mappings and line scans of elemental distribution are shown in Figure 1e2-e6. Obviously, the element signal intensity varies with the position of the core-shell microrods. Figure 1e2,e5,e6 reveal $\mathrm{Yb}$ is uniformly distributed in the core, and Figure 1e3-e6 describe $\mathrm{Tb}$ and $\mathrm{Eu}$ are uniformly distributed in the shell. This is consistent with the designed element distribution, and further validates the synthesis of core-shell structure. The crystalline seed rods and core-shell microrods can be confirmed by the XRD patterns. As shown in Figure 1f, all the peaks of samples can be indexed to the standard pattern of hexagonal-phase $\mathrm{NaYF}_{4}$ microrods (JSPDS No. 16-0334), indicating the formation of pure hexagonal-phase $\mathrm{NaYF}_{4}$ microrods for the core and core-shell-structured samples. 

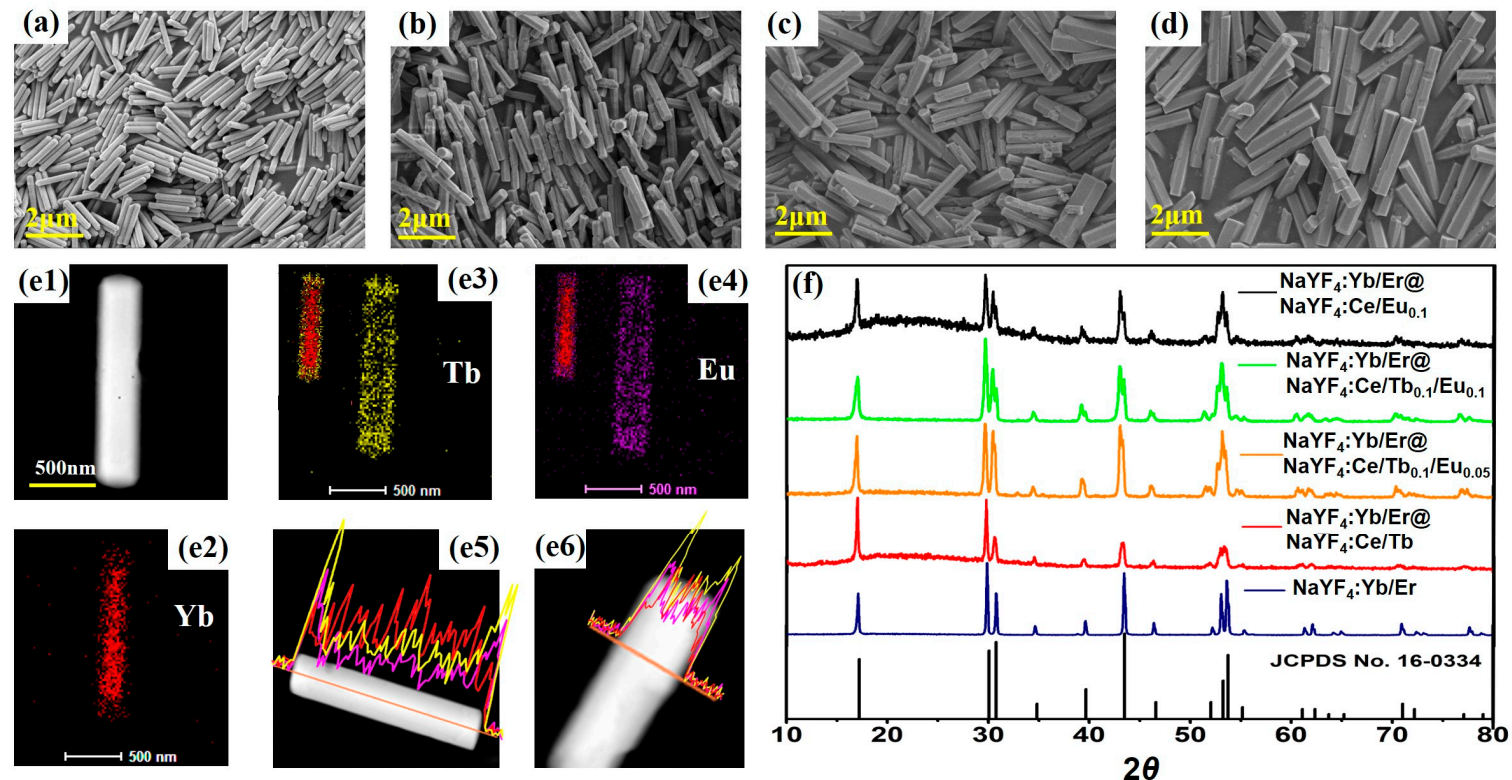

Figure 1. (a-d) SEM imaging of the samples, $\mathrm{NaYF}_{4}: \mathrm{Yb} / \mathrm{Er}, \mathrm{NaYF}_{4}: \mathrm{Yb} / \mathrm{Er} @ \mathrm{NaYF}_{4}: \mathrm{Ce} / \mathrm{Tb}_{0.1}$, $\mathrm{NaYF}_{4}: \mathrm{Yb} / \mathrm{Er} @ \mathrm{NaYF}_{4}: \mathrm{Ce} / \mathrm{Tb}_{0.1} / \mathrm{Eu}_{0.05}, \mathrm{NaYF}_{4}: \mathrm{Yb} / \mathrm{Er} @ \mathrm{NaYF}_{4}: \mathrm{Ce} / \mathrm{Eu}_{0.1}$ microrods. (e1) The STEM image of the $\mathrm{NaYF}_{4}: \mathrm{Yb} / \mathrm{Er}_{\mathrm{NaYF}}: \mathrm{Ce} / \mathrm{Tb}_{0.1} / \mathrm{Eu}_{0.05}$ microrods. (e2-e4) are the element mappings of $\mathrm{Yb}, \mathrm{Tb}$ and $\mathrm{Eu}$ in a single $\mathrm{NaYF}_{4}: \mathrm{Yb} / \mathrm{Er} @ \mathrm{NaYF}_{4}: \mathrm{Ce} / \mathrm{Tb}_{0.1} / \mathrm{Eu}_{0.05}$ microrod, respectively. The insets in Figure (e3,e4) are the element composition images of $\mathrm{Yb}-\mathrm{Tb}$ and $\mathrm{Yb}-\mathrm{Eu}$, respectively. (e5,e6) are line scans of the element distributions of $\mathrm{Yb}, \mathrm{Tb}$ and $\mathrm{Eu}$ in the single microrod along the axial direction and radial direction, respectively. The red, yellow, and purple lines represent the $\mathrm{Yb}, \mathrm{Tb}$ and Eu elements, respectively. (f) XRD patterns of the samples.

The UC luminescence spectra of samples $\left(\mathrm{NaYF}_{4}: \mathrm{Yb} / \mathrm{Er}\right.$ and $\mathrm{NaYF}_{4}: \mathrm{Yb} / \mathrm{Er} @ \mathrm{NaYF}_{4}: \mathrm{Ce} /$ $\mathrm{Tb}_{0.1} / \mathrm{Eu}_{0.01}$ ) are illustrated in Figure 2. Under excitation at $980 \mathrm{~nm}$, the core and core-shell microrods all exhibit three emission bands, which stem from the ${ }^{2} \mathrm{H}_{11 / 2} \rightarrow{ }^{4} \mathrm{I}_{15 / 2}(523 \mathrm{~nm}),{ }^{4} \mathrm{~S}_{3 / 2} \rightarrow{ }^{4} \mathrm{I}_{15 / 2}(541 \mathrm{~nm})$ and ${ }^{4} \mathrm{~F}_{9 / 2} \rightarrow{ }^{4} \mathrm{I}_{15 / 2}(656 \mathrm{~nm})$ transitions from $\mathrm{Er}^{3+}$. This result indicates coating the shell hardly hinder the UC process of the seed crystals. However, it is easily noticed that the green-to-red intensity ratio of core-shell microrods is higher than that of core microrods. The Commission Internationale de $1^{\prime}$ Eclairage (CIE) coordinates of core and core-shell microrods are $(0.422,0.563)$ and $(0.367,0.611)$, respectively (Figure S2). Our group has reported that the UC luminescence intensity of the core-shell microrods decreases after shell coating modification [15,32].

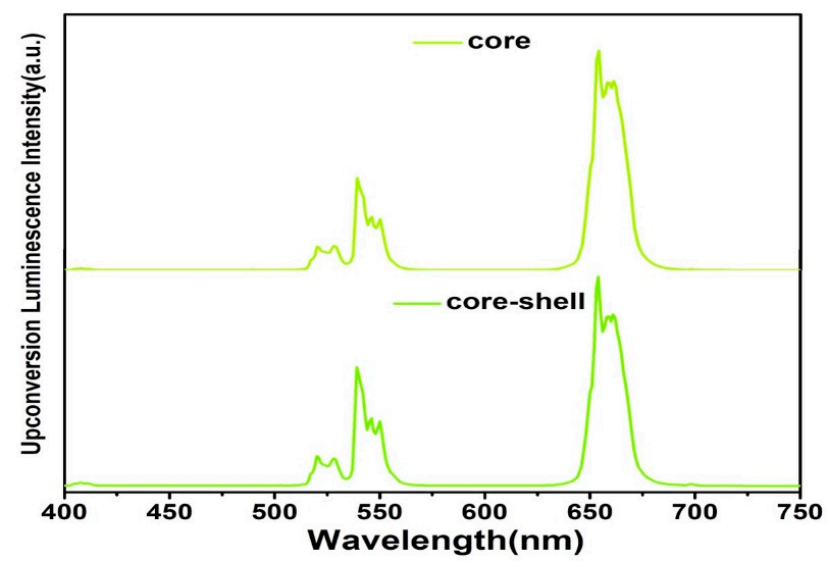

Figure 2. Emission spectra of the seed microcrystals $\left(\mathrm{NaYF}_{4}: \mathrm{Yb} / \mathrm{Er}\right.$, upper) and core-shell microrods $\left(\mathrm{NaYF}_{4}: \mathrm{Yb} / \mathrm{Er} @ \mathrm{NaYF}_{4}: \mathrm{Ce} / \mathrm{Tb}_{0.1} / \mathrm{Eu}_{0.1}\right.$, lower) under $980 \mathrm{~nm}$ excitation. 
The DS luminescence spectra of the core-shell microrods under UV light are shown in Figures 3-5. Figure 3 a shows the photoluminescence excitation spectra of core-shell microrods monitored at $544 \mathrm{~nm}$ from $\mathrm{Tb}^{3+}$. The shell doped with $\mathrm{Ce}^{3+}$ and $\mathrm{Tb}^{3+}$ ions shows one main absorption band peak at $252 \mathrm{~nm}$, which results from $4 \mathrm{f} \rightarrow 5 \mathrm{~d}$ transition from $\mathrm{Ce}^{3+}$ ions $[21,22,26]$. The corresponding emission spectra of $\mathrm{NaYF}_{4}: \mathrm{Yb} / \mathrm{Er} @ \mathrm{NaYF}_{4}: \mathrm{Ce} / \mathrm{Tb} / \mathrm{Eu}$ microrods are displayed in Figure 3b when excited at $252 \mathrm{~nm}$ directly. The emission spectra are recorded by characteristic transition for both $\mathrm{Tb}^{3+}$ and $\mathrm{Eu}^{3+}$ in the visible region [25-28]. The emission peaks at 489, 544, 584 and $620 \mathrm{~nm}$ due to electronic transition from $\mathrm{Tb}^{3+}$ ions $\left({ }^{5} \mathrm{D}_{4} \rightarrow{ }^{7} \mathrm{~F}_{\mathrm{J}}(\mathrm{J}=6,5,4\right.$, and 3$\left.)\right)$ are observed. This indicates that the $\mathrm{Ce}^{3+}$ ions absorb UV light and transfer energy to neighboring $\mathrm{Tb}^{3+}$ ions, resulting in the luminescence emission from $\mathrm{Tb}^{3+}$ ions. As discussed by previous reports [19,27-29], the $\mathrm{Tb}^{3+}$ and $\mathrm{Eu}^{3+}$ ions are utilized together to achieve the tunable color and obtain bright multicolor emission. Therefore, we reported the $\mathrm{NaYF}_{4}: \mathrm{Ce} / \mathrm{Tb} / \mathrm{Eu}$ shells are grown on the UC microrods. With the increasing concentration of Eu ${ }^{3+}$ ions in shells, the intensity of emission bands from $\mathrm{Tb}^{3+}$ ions suffer from quenching, whereas the intensity of the Eu $\mathrm{E}^{3+}$ is enhanced (Figure $3 b$ ). Figure $3 b$ shows that the emission spectra exhibit the strong emission bands of $\mathrm{Eu}^{3+}$ ions at 590, 615 and $695 \mathrm{~nm}$ when the concentration of $\mathrm{Eu}^{3+}$ is above $2 \mathrm{~mol} \%$. The strongest emission peak is $615 \mathrm{~nm}$. The three emission bands of $\mathrm{Eu}^{3+}$ are attributed to ${ }^{5} \mathrm{D}_{0} \rightarrow{ }^{7} \mathrm{~F}_{\mathrm{J}}(\mathrm{J}=1,2$, and 4) transition, respectively. This result indicates that the $\mathrm{Tb}^{3+}$ ions act as intermediate ions to achieve $\mathrm{Ce}^{3+} \rightarrow \mathrm{Tb}^{3+} \rightarrow \mathrm{Eu}^{3+}$ energy transfer.
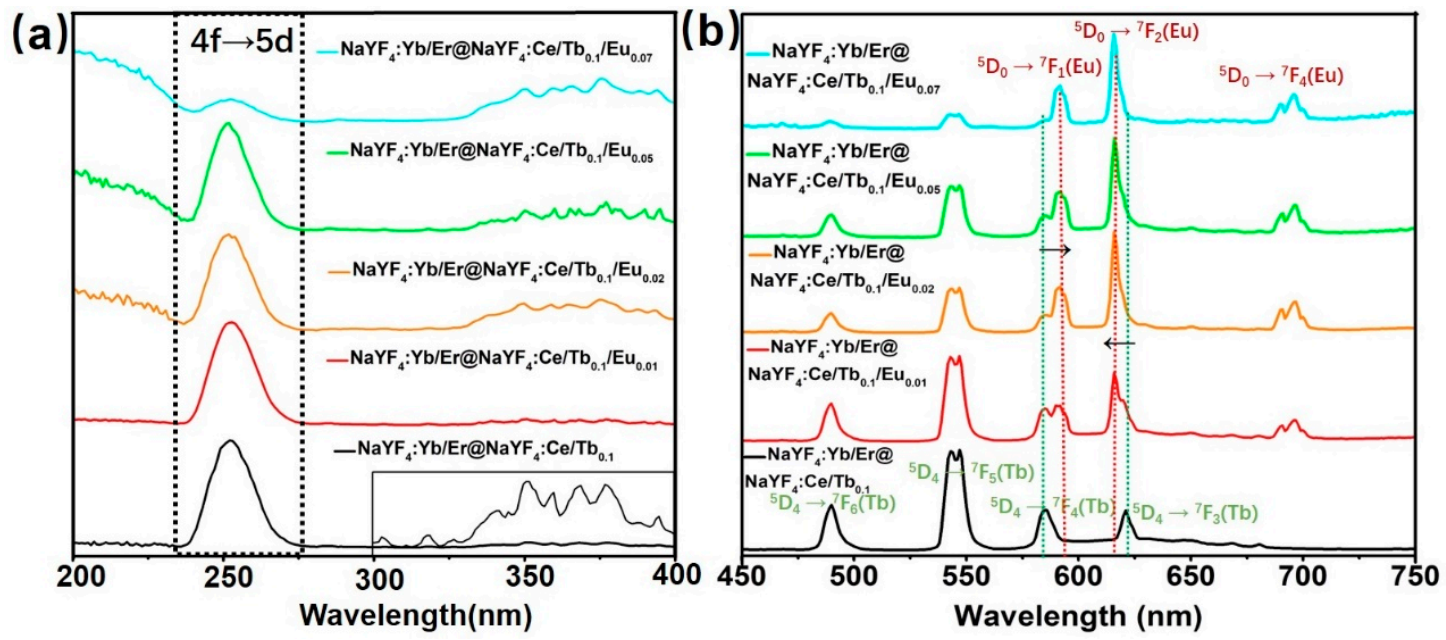

Figure 3. (a) Photoluminescence excitation (PLE) spectra of core-shell-structured microrods monitored at $544 \mathrm{~nm}$ from $\mathrm{Tb}^{3+}$. The inset is the enlarged excitation spectrum of the sample from $300 \mathrm{~nm}$ to $400 \mathrm{~nm}$. (b) Emission spectra of corresponding samples at $252 \mathrm{~nm}$ excitation under the same condition.

To comprehend the energy transfer, the decay curves of $\mathrm{Tb}^{3+}$ emission at $544 \mathrm{~nm}$ and energy transfer efficiency $\left(\eta_{\mathrm{Tb}-\mathrm{Eu}}\right)$ from $\mathrm{Tb}^{3+}$ to $\mathrm{Eu}^{3+}$ of core-shell microrods are presented in Figure 4 . Figure $4 \mathrm{a}$ demonstrates the lifetime curve of the $\mathrm{NaYF}_{4}: \mathrm{Yb} / \mathrm{Er} @ \mathrm{NaYF}_{4}: \mathrm{Ce} / \mathrm{Tb}_{0.1} / \mathrm{Eu}_{\mathrm{x}}(\mathrm{x}=0,0.02$, and 0.07) under a pulsed excitation wavelength of $252 \mathrm{~nm}$. The effective lifetime of the excited state was calculated according to the equation: $\tau_{\text {eff }}=\int \mathrm{I}(t) \mathrm{d} t / \mathrm{I}_{0}$, where $\mathrm{I}(\mathrm{t})$ is the luminescence intensity at time $\mathrm{t}$ and $\mathrm{I}_{0}$ represents the maximum intensity [33]. It is worthy to notice here that by increasing the $E \mathrm{u}^{3+}$ concentration from 0 to $7 \mathrm{~mol} \%$ in the shell, the lifetime of $\mathrm{Tb}^{3+}$ emission at $544 \mathrm{~nm}$ decreases from $5.99 \mathrm{~ms}$ to $1.46 \mathrm{~ms}$. For more thoroughly investigating the energy transfer of $\mathrm{Tb}^{3+}$ and $\mathrm{Eu}^{3+}$ ions, the $\eta_{T b-E u}$ was also calculated by the following equation $[21,29]$ :

$$
\eta_{T b \rightarrow E u}=1-\frac{I}{I_{0}}
$$


where $I$ and $I_{0}$ are the emission intensities of the $\mathrm{Tb}^{3+}$ ions at $544 \mathrm{~nm}$ with and without $\mathrm{Eu}^{3+}$ ions, respectively. The $\eta_{T b-E u}$ was calculated as a function of doping concentration of $\mathrm{Eu}^{3+}$, as shown in Figure $4 \mathrm{~b}$. It is found that the $\eta_{T b-E u}$ increases rapidly with the increasing $\mathrm{Eu}^{3+}$ concentration. The $\eta_{T b-E u}$ increases to $97.9 \%$ at $\mathrm{NaYF}_{4}: \mathrm{Yb} / \mathrm{Er} @ \mathrm{NaYF}_{4}: \mathrm{Ce} / \mathrm{Tb}_{0.1} / \mathrm{Eu}_{0.7}$ microrods. The phenomenon indicates efficient $\mathrm{Tb}^{3+} \rightarrow \mathrm{Eu}^{3+}$ energy transition and achievement of the tunable color emission. The CIE coordinates of $\mathrm{NaYF}_{4}: \mathrm{Yb} / \mathrm{Er} @ \mathrm{NaYF}_{4}: \mathrm{Ce} / \mathrm{Tb}_{0.1} / \mathrm{Eu}$ microrods shift from $(0.414,0.517)$ to $(0.488$, 0.383 ) by tuning the concentration of $\mathrm{Eu}^{3+}$ from 0 to $0.07 \mathrm{~mol} \%$ (Figure S3). This means the emission color of samples shifts from yellow-green to orange under UV lamp $(\lambda=252 \mathrm{~nm})$ excitation.
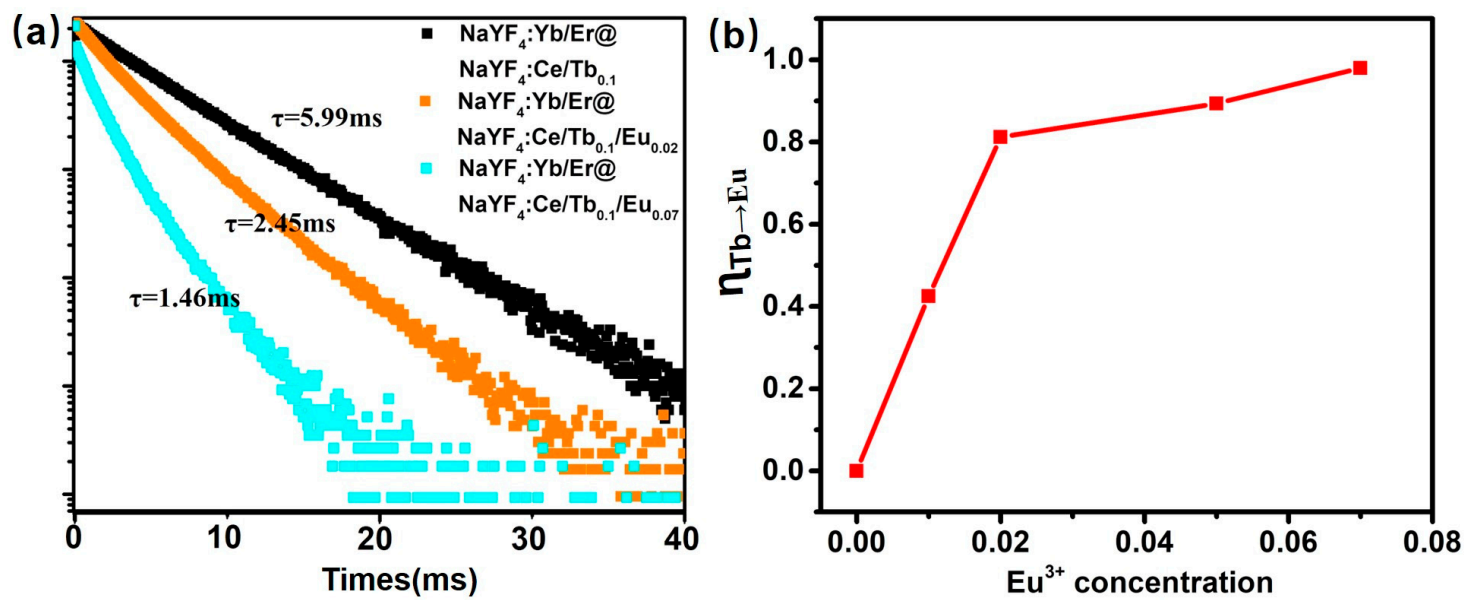

Figure 4. (a) Downshifting luminescence delay curve of core-shell-structured microrods at $544 \mathrm{~nm}$ with various doping concentrations of $\mathrm{Tb}^{3+}$ and $\mathrm{Eu}^{3+}$. (b) Energy transfer efficiency from $\mathrm{Tb}^{3+}$ to $\mathrm{Eu}^{3+}$ in NaYF4:Yb/Er@NaYF $4: \mathrm{Ce} / \mathrm{Tb}_{0.1} /$ Eu microrods doped with various Eu concentrations.

Besides, DS emission from $\mathrm{Eu}^{3+}$ ions in core-shell microrods is also obtained under $395 \mathrm{~nm}$ excitation directly. The excitation spectra and emission spectra of core-shell microrods by doping $\mathrm{Eu}^{3+}$ in the shells are shown in Figure 5. The PLE spectra of samples, monitoring emission at $615 \mathrm{~nm}$ (Figure 5a), contain two main peaks at $252 \mathrm{~nm}$ and $395 \mathrm{~nm}$. It is noticed that the PLE spectra of samples by co-doping $\mathrm{Tb}^{3+}$ and $\mathrm{Eu}^{3+}$ ions include all spectral features for co-doped $\mathrm{Ce} / \mathrm{Tb}$ and $\mathrm{Ce} / \mathrm{Eu}$ ions (Figures $3 \mathrm{a}$ and $5 \mathrm{a}$ ). The excitation band centered at $252 \mathrm{~nm}$ suggests the energy transition process from $\mathrm{Ce}^{3+}$ to $\mathrm{Eu}^{3+}$ via $\mathrm{Tb}^{3+}$, as discussed above. As the doping concentration of $\mathrm{Eu}^{3+}$ increases in the shells, the emission band peak at $395 \mathrm{~nm}$ is dominant, which is attributed to ${ }^{7} \mathrm{~F}_{0} \rightarrow{ }^{5} \mathrm{~L}_{6}$ transition of Eu ${ }^{3+}$ ions (Figure 5a). According to Figure $5 \mathrm{a}, \mathrm{NaYF}_{4}: \mathrm{Yb} / \mathrm{Er}_{\mathrm{NaYF}}: \mathrm{Ce} / \mathrm{Tb} / \mathrm{Eu}$ microrods can be excited directly by $395 \mathrm{~nm}$ light, which is the characteristic excitation band of $\mathrm{Eu}^{3+}$, as previously reported [16,34]. The corresponding emission spectra of the samples at $395 \mathrm{~nm}$ excitation are shown in Figure 5b. Independent of the doping of $\mathrm{Ce}^{3+}$ and $\mathrm{Tb}^{3+}$ ions, the emission spectra profiles are the same (Figure $5 \mathrm{~b}$, and Figure S4), consisting of characteristic peaks of Eu ${ }^{3+}$ due to ${ }^{5} \mathrm{D}_{0} \rightarrow{ }^{7} \mathrm{~F}_{\mathrm{J}}(\mathrm{J}=1,2$, and 4) transition. The luminescence intensity increases with the Eu content (Figure S4). However, the intensity ratios of the emission bands change as a function of $\mathrm{Eu}^{3+}$ concentration in samples under the same excitation condition (Figure S5). This is ascribed to the influence of symmetry of host lattice on ${ }^{5} \mathrm{D}_{0} \rightarrow{ }^{7} \mathrm{~F}_{2}$ transition [19]. Hence, the emission color of core-shell microrods gradually changes from orange to red, and the corresponding CIE color coordinates of these samples are shown in Figure S3b. The coordinates shift from $(0.525,0.457)$ to $(0.459,0.437)$. As a result, the $\mathrm{NaYF}_{4}: \mathrm{Yb} / \mathrm{Er} @ \mathrm{NaYF} 4 \mathrm{Ce} / \mathrm{Tb} / \mathrm{Eu}$ microrods can emit visible light from yellow-green to red color by adjusting the concentrations of $\mathrm{Tb}^{3+}$ and $\mathrm{Eu}^{3+}$ in shells and UV excitation wavelengths. 

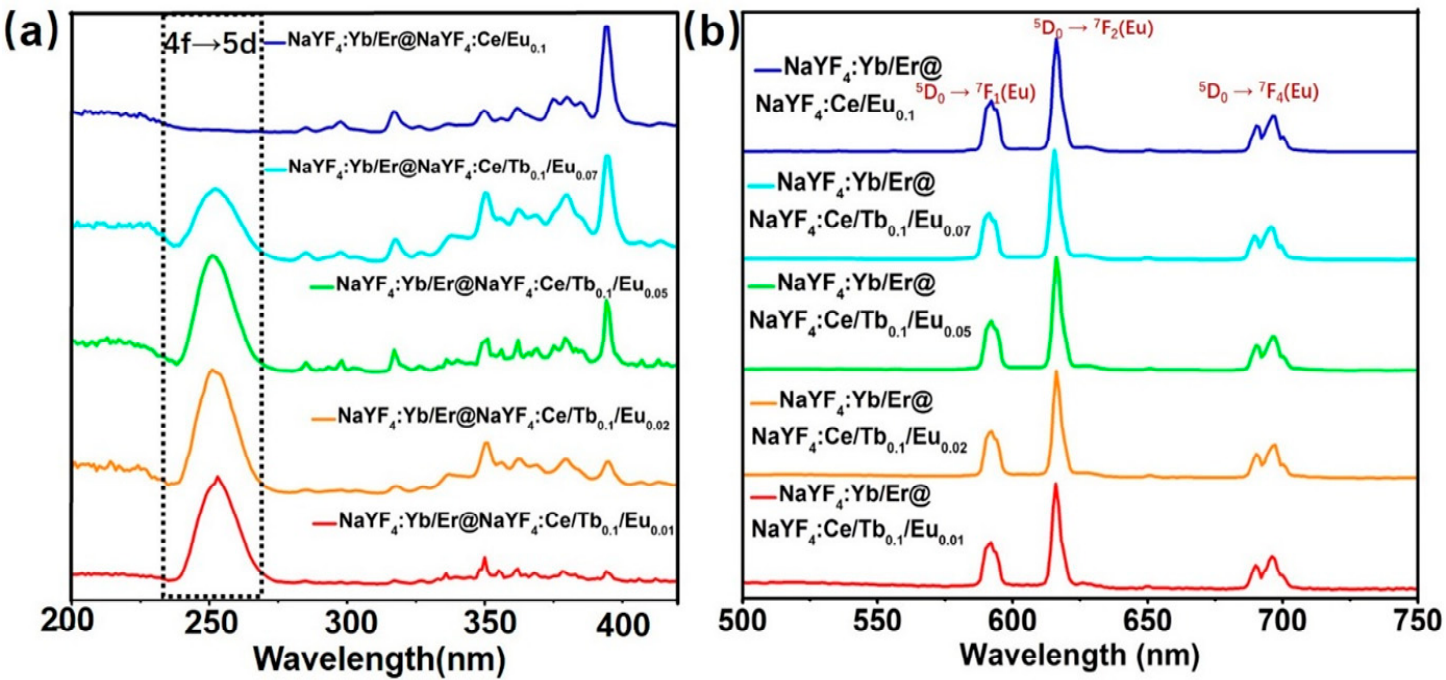

Figure 5. (a) Photoluminescence excitation spectra of core-shell-structured microrods monitored at $615 \mathrm{~nm}$ from $\mathrm{Eu}^{3+}$. (b) Emission spectra of corresponding samples at $395 \mathrm{~nm}$ excitation under the same condition.

Owing to the coexistent DS emission from $\mathrm{Tb}^{3+}$ and $\mathrm{Eu}^{3+}$ under $252 \mathrm{~nm}$ excitation, the separation of DS emission between $\mathrm{Tb}^{3+}$ and $\mathrm{Eu}^{3+}$ could be achieved by time-resolved luminescence detection technique, which is ascribed to their different decay lifetimes (Figure S6). In Figure S6a, it is noticed that the decay time of $\mathrm{Eu}^{3+}$ emission is longer than that of $\mathrm{Eu}^{3+}$ emission in previous reported. This is because the lifetime of the excited state is affected by the host and the synthesis procedure. The longer lifetime of $\mathrm{Eu}^{3+}$ ions is obtained when the $\mathrm{Eu}^{3+}$ ions are in a more symmetric environment [19]. On the other hand, the transient curve of $\mathrm{Eu}^{3+}$ emission exhibits rise and decay components, which indicates the energy transfer process [35]. The curve can be well fitted with the following equation [36]:

$$
I(t)=-A e^{-t / \tau_{r}}+B_{1} e^{-t / \tau_{1}}+B_{2} e^{-t / \tau_{2}}
$$

where $A, B_{1}$ and $B_{2}$ are emission intensity constants, and $\tau_{r}$ and $\tau_{1,2}$ represent the rise and delay time, respectively. The calculated rise time of the $\mathrm{NaYF}_{4}: \mathrm{Yb} / \mathrm{Er} @ \mathrm{NaYF}_{4}: \mathrm{Ce} / \mathrm{Tb}_{0.1} / \mathrm{Eu}_{0.05}$ microrods is $1.97 \mathrm{~ms}$. Furthermore, we calculated rise time of other samples with various concentrations of $\mathrm{Eu}^{3+}$ ions. The rise time of the emission at $615 \mathrm{~nm}$ decreases with the increasing concentration, as shown in Figure S6b, which is attributed to the distance of energy transition becoming shorter with increasing concentration of $\mathrm{Eu}^{3+}$ ions $[34,37,38]$.

Figure 6a shows the time-resolved emission spectra (TRES) for $\mathrm{NaYF}_{4}: \mathrm{Yb} / \mathrm{Er} @ \mathrm{NaYF}_{4}: \mathrm{Ce} /$ $\mathrm{Tb}_{0.1} / \mathrm{Eu}_{0.05}$ microrods by setting various delay times at $252 \mathrm{~nm}$ excitation. The long delay time emission of $\mathrm{Eu}^{3+}$ could be distinguished from that of $\mathrm{Tb}^{3+}$, which means in the long delay time $(>8 \mathrm{~ms})$, the whole DS emission is dominated by the red emission from $\mathrm{Eu}^{3+}$ using UV lamp ( $\left.252 \mathrm{~nm}\right)$ excitation. At the same time, the emission from $\mathrm{Tb}^{3+}$ is prominent by setting the short delay time $(0.8-8 \mathrm{~ms})$. This indicates that the emission multicolor outputs, changing from green to red region, in the time domain from $\mathrm{NaYF}_{4}: \mathrm{Yb} / \mathrm{Er} @ \mathrm{NaYF}_{4}: \mathrm{Ce} / \mathrm{Tb}_{0.1} / \mathrm{Eu}_{0.05}$ microrods could be achieved by setting suitable delay time. The corresponding CIE coordinates are shown in Figure 6b. The DS multicolor outputs (time-resolved and pump-wavelength-induced DS) coupled with the UC mode could pave the way for the anti-counterfeiting fields. 

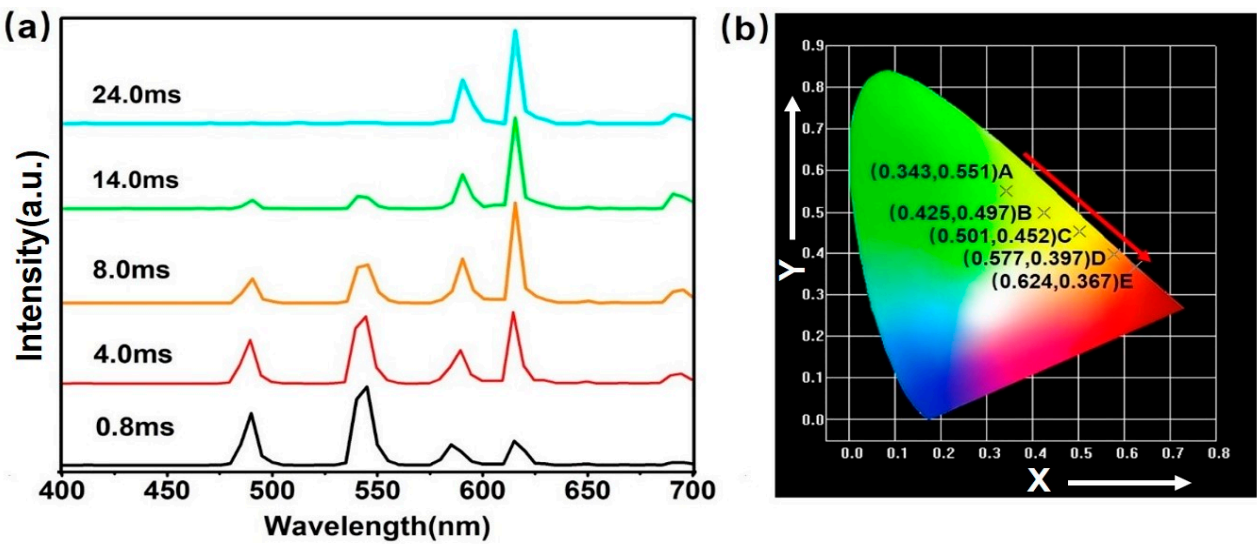

Figure 6. (a) Time-resolved emission spectra for $\mathrm{NaYF}_{4}: \mathrm{Yb} / \mathrm{Er} @ \mathrm{NaYF}_{4}: \mathrm{Ce} / \mathrm{Tb}_{0.1} / \mathrm{Eu}_{0.05}$ microrods at $252 \mathrm{~nm}$ excitation. (b) The CIE coordinates of the sample at various delay times.

We successfully fabricated the core-shell microrods that can realize dual-mode (UC and DS) luminescence from $\mathrm{Er}^{3+}, \mathrm{Tb}^{3+}$ and $\mathrm{Eu}^{3+}$ ions. The schematic of the prepared core-shell microrods is shown in Figure 7a. Efficient UC luminescence can be obtained with $980 \mathrm{~nm}$ laser irradiation, giving rise to the emission of green, red or yellow colors. As the shell is doped with $\mathrm{Ce}^{3+} / \mathrm{Tb}^{3+} / \mathrm{Eu}^{3+}$ ions, $\mathrm{Ce}^{3+}$ ion will act as a sensitizer and promote the energy transition to activators $\left(\mathrm{Tb}^{3+}\right.$ ions). Podhorodecki [25] and Jang [26] have confirmed the excitation of Eu ions through $\mathrm{Tb}$ ions due to the similar excitation spectra recorded for emission of $\mathrm{Eu}^{3+}$ ions between $\mathrm{NaYF}_{4}: \mathrm{Tb}, \mathrm{Eu}$ and $\mathrm{NaYF}_{4}: \mathrm{Eu}$ samples. It indicates that the excitation energy can be transferred from $\mathrm{Ce}^{3+}$ to $\mathrm{Eu}^{3+}$ ions. Meanwhile, red DS emission from $\mathrm{Eu}^{3+}$ ions is also obtained under $395 \mathrm{~nm}$ excitation.

(a)

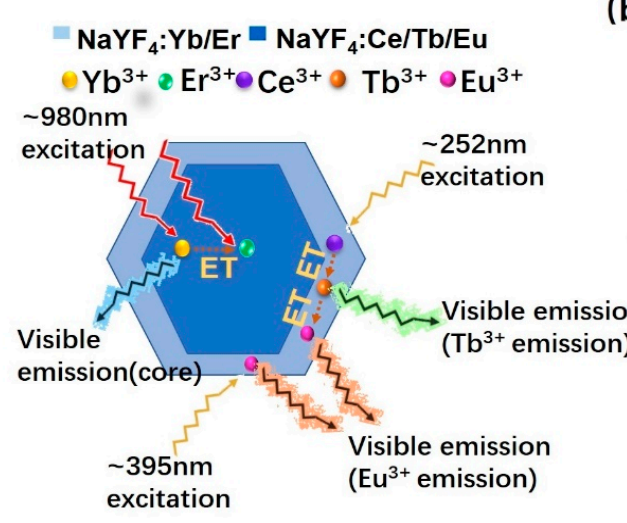

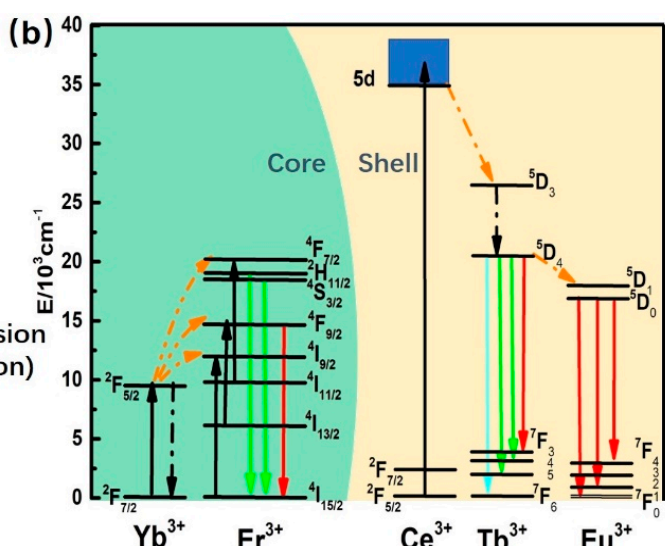

Figure 7. (a) Schematic illustration of $\mathrm{NaYF}_{4}: \mathrm{Yb} / \mathrm{Er} @ \mathrm{NaYF}_{4}: \mathrm{Ce} / \mathrm{Tb} / \mathrm{Eu}$ core-shell microcrystals to achieve the dual-mode emission. (b) Proposed schematic diagram of the energy transfer processes for dual-mode emission in the core-shell microrods.

The luminescence mechanism for $\mathrm{NaYF}_{4}: \mathrm{Yb} / \mathrm{Er} @ \mathrm{NaYF}_{4}: \mathrm{Ce} / \mathrm{Tb} / \mathrm{Eu}$ core-shell microcrystals system is displayed in Figure $7 \mathrm{~b}$. The UC luminescence can be obtained from core microrods at $980 \mathrm{~nm}$ excitation, which stems from the 4 f electronic transition of $\mathrm{Er}^{3+}[22,32]$. Under $980 \mathrm{~nm}$ excitation, $\mathrm{Yb}^{3+}$ ions transfer energy to $\mathrm{Er}^{3+}$ after absorbing excitation energy. The excitation levels $\left({ }^{2} \mathrm{H}_{11 / 2} /{ }^{4} \mathrm{~S}_{3 / 2},{ }^{4} \mathrm{~F}_{9 / 2}\right.$ states) of $\mathrm{Er}^{3+}$ are populated via two successive energy transition processes (Figure S7), and green $(\sim 540 \mathrm{~nm})$ and red $(\sim 654 \mathrm{~nm})$ emissions are generated. For the $\mathrm{Ce}^{3+}-\mathrm{Tb}^{3+}-\mathrm{Eu}^{3+}$ system in shells, the DS emission can be achieved. The $\mathrm{Ce}^{3+}$ ions absorb the external UV light $(\sim 252 \mathrm{~nm})$ due to $4 \mathrm{f} \rightarrow 5 \mathrm{~d}$ transition and then transfer to ${ }^{5} \mathrm{D}_{4}$ state of $\mathrm{Tb}^{3+}$ ions efficiently (Figure 4). Afterwards, the green emission is obtained through the radiative transition from ${ }^{5} \mathrm{D}_{4}$ state to ${ }^{7} \mathrm{~F}_{\mathrm{J}}(\mathrm{J}=3,4,5$, and 6) states. With $\mathrm{Eu}^{3+}$ ions doping, $\mathrm{Tb}^{3+} \rightarrow \mathrm{Eu}^{3+}$ energy transfer occurs, and a part of excited energy from ${ }^{5} \mathrm{D}_{4}$ 
state of $\mathrm{Tb}^{3+}$ ions shifts to ${ }^{5} \mathrm{D}_{0}$ state. Finally, the red emission is generated ascribed to ${ }^{5} \mathrm{D}_{0} \rightarrow{ }^{7} \mathrm{~F}_{\mathrm{J}}$ $(\mathrm{J}=1,2,4)$ transition. In addition, the red emission from $\mathrm{Eu}^{3+}$ can also be obtained using $395 \mathrm{~nm}$ excitation straightforwardly.

\section{Conclusions}

We have successfully designed an approach to achieve UC and DS luminescence simultaneously in core-shell microrods $\left(\mathrm{NaYF}_{4}: \mathrm{Yb} / \mathrm{Er} @ \mathrm{NaYF}_{4}: \mathrm{Ce} / \mathrm{Tb} / \mathrm{Eu}\right)$. This approach helps confine the activators to different regions, hence overcoming the effect of the cross-relaxations between activators, and meanwhile minimizing the effect of surface quenching without an outmost layer. The $\mathrm{NaYF}_{4}: \mathrm{Yb} / \mathrm{Er} @ \mathrm{NaYF}_{4}: \mathrm{Ce} / \mathrm{Tb} / \mathrm{Eu}$ microrods could achieve multicolor emission depending on excitation wavelengths $(980 \mathrm{~nm}, 252 \mathrm{~nm}$, and $395 \mathrm{~nm})$, the concentration of $\mathrm{Eu}^{3+}$ in shells and detection delay time. Under the $980 \mathrm{~nm}$ excitation, the core of $\mathrm{Yb} / \mathrm{Er}$ system for the UC process emits yellow color. While, the shell of $\mathrm{Ce} / \mathrm{Tb} / \mathrm{Eu}$ systems for the DS process emits visible light from yellow-green to red color by adjusting the concentrations of $\mathrm{Eu}^{3+}$ and UV excitation wavelengths $(252 \mathrm{~nm}$, and $395 \mathrm{~nm})$. Moreover, because of the different decay lifetime of $\mathrm{Tb}^{3+}$ and $\mathrm{Eu}^{3+}$ ions at their characteristic emission wavelengths, the emission multicolor outputs, changing from green to red region, in the time domain from $\mathrm{NaYF}_{4}: \mathrm{Yb} / \mathrm{Er} @ \mathrm{NaYF}_{4}: \mathrm{Ce} / \mathrm{Tb}_{0.1} / \mathrm{Eu}_{0.05}$ microrods could be realized by optimizing delay time. Due to high UC/DS efficiency and dual-mode luminescence with multicolor emission, the $\mathrm{NaYF}_{4}: \mathrm{Yb} / \mathrm{Er} @ \mathrm{NaYF}_{4}: \mathrm{Ce} / \mathrm{Tb} / \mathrm{Eu}$ microrods have promising applications in displays and anti-counterfeiting fields.

Supplementary Materials: The following are available online at http:/ /www.mdpi.com/2079-4991/8/12/1023/ s1, Figure S1: Size distribution analysis of the $\mathrm{NaYF}_{4}: \mathrm{Yb} / \mathrm{Er} @ \mathrm{NaYF}_{4}: \mathrm{Ce} / \mathrm{Tb} / \mathrm{Eu}$ microcrystals along the axial direction (a) and radial direction $(\mathbf{b})$ collected at various doping concentration ratios of Tb/Eu, Figure S2: The $\mathrm{CIE}$ chromaticity coordinates of the emission of the seed microcrystals $\left(\mathrm{NaYF}_{4}: \mathrm{Yb} / \mathrm{Er}\right)$ and core-shell microrods $\left(\mathrm{NaYF}_{4}: \mathrm{Yb} / \mathrm{Er} @ \mathrm{NaYF}_{4}: \mathrm{Ce} / \mathrm{Tb}_{0.1} / \mathrm{Eu}_{0.1}\right)$ under $980 \mathrm{~nm}$ excitation, Figure S3: CIE chromaticity coordinates of the emission of samples with various doping concentrations of $\mathrm{Tb}^{3+}$ and $\mathrm{Eu}^{3+}$. The direction of the arrow denotes the changing of emission colors, Figure S4: Pump-power-dependent downshifting luminescence spectra of the core-shell-structured microrods with various doping concentration ratios of $\mathrm{Tb} / \mathrm{Eu}$ under $395 \mathrm{~nm}$ excitation, Figure S5: Relative intensity of different emission bands in core-shell microrods under $395 \mathrm{~nm}$ irradiation, Figure S6: (a) Delay curves of $\mathrm{NaYF}_{4}: \mathrm{Yb} / \mathrm{Er} @ \mathrm{NaYF}_{4}: \mathrm{Ce} / \mathrm{Tb}_{0.1} / \mathrm{Eu}_{0.05}$ microrods at $544 \mathrm{~nm}$ and $615 \mathrm{~nm}$ under 252 $\mathrm{nm}$ excitation, (b) rise time of emission at $615 \mathrm{~nm}$ for $\mathrm{NaYF} 4: \mathrm{Yb} / \mathrm{Er} @ \mathrm{NaYF}_{4}: \mathrm{Ce} / \mathrm{Tb}_{0.1} / \mathrm{Eu}$ microrods doped with different Eu concentrations, Figure S7: (a) Pump-power-dependent upconversion luminescence spectra of the core-shell-structured microrods $\left(\mathrm{NaYF}_{4}: \mathrm{Yb} / \mathrm{Er} @ \mathrm{NaYF}_{4}: \mathrm{Ce} / \mathrm{Tb}_{0.1} / \mathrm{Eu}_{0.01}\right)$ using $980 \mathrm{~nm}$ excitation and (b) corresponding log-log plots of upconversion emission intensity versus excitation power.

Author Contributions: D.J. and F.S. (Feng Song) conceived and designed the experiments; D.J. performed the experiments; D.J. analyzed the data; F.S. (Feifei Song), A.Z. and X.G. contributed analysis tools; D.J. wrote the paper; H.H. and X.S. gave advices; A.K., V. Z. and F.S. (Feng Song) reviewed and edited the manuscript. All of the authors read and approved the manuscript.

Acknowledgments: This work is financially supported by the Nature Science Foundation of China (No. 11674183, 11811530075), the Natural Science Foundation of Tianjin, key project (No. 17JCZDJC37800), and 111 Project (No. B07013).

Conflicts of Interest: The authors declare no conflicts of interest.

\section{References}

1. Liu, Y.; Tu, D.; Zhu, H.; Li, R.; Luo, W.; Chen, X. A strategy to achieve efficient dual-mode luminescence of $\mathrm{Eu}^{3+}$ in lanthanides doped multifunctional $\mathrm{NaGdF}_{4}$ nanocrystals. Adv. Mater. 2010, 22, 3266-3271. [CrossRef] [PubMed]

2. Han, Y.; Gao, C.; Wang, Y.; Ju, D.; Zhou, A.; Song, F.; Huang, L.; Huang, W. Spatially confined luminescence process in tip-modified heterogeneous-structured microrods for high-level anti-counterfeiting. Phys. Chem. Chem. Phys. 2018, 20, 9516-9522. [CrossRef] [PubMed]

3. Wen, S.; Zhou, J.; Zheng, K.; Bednarkiewicz, A.; Liu, X.; Jin, D. Advances in highly doped upconversion nanoparticles. Nat. Commun. 2018, 9, 2415. [CrossRef] [PubMed] 
4. Wang, F.; Han, Y.; Lim, S.C.; Lu, Y.H.; Wang, J.; Xu, J.; Chen, H.Y.; Zhang, C.; Hong, M.H.; Liu, X.G. Simultaneous phase and size control of upconversion nanocrystals through lanthanide doping. Nature 2010, 463, 1060-1065. [CrossRef] [PubMed]

5. Richards, B.S. Luminescent layers for enhanced silicon solar cell performance: Down-conversion. Solar Energy Mater. Solar Cells 2006, 90, 1189-1207. [CrossRef]

6. Zheng, K.; Han, S.; Zeng, X.; Wu, Y.; Song, S.; Zhang, H.; Liu, X. Rewritable optical memory through high-registry orthogonal upconversion. Adv. Mater. 2018, 30, 1801726. [CrossRef] [PubMed]

7. Gu, M.; Zhang, Q.; Lamon, S. Nanomaterials for optical data storage. Nat. Rev. Mater. 2016, 1, 16070. [CrossRef]

8. Lei, L.; Chen, D.; Li, C.; Huang, F.; Zhang, J.; Xu, S. Inverse thermal quenching effect in lanthanide-doped upconversion nanocrystals for anti-counterfeiting. J. Mater. Chem. C 2018, 6, 5427-5433. [CrossRef]

9. Wang, H.; Yin, X.; Xing, M.; Fu, Y.; Tian, Y.; Feng, X.; Jiang, T.; Luo, X. Thermal effects of $\mathrm{Er}^{3+} / \mathrm{Yb}^{3+}$-doped $\mathrm{NaYF}_{4}$ phosphor induced by 980/1510 nm laser diode irradiation. J. Am. Ceram. Soc. 2018, 101, 865-873. [CrossRef]

10. Zhou, A.; Song, F.; Han, Y.; Song, F.F.; Ju, D.; Wang, X. Simultaneous size adjustment and upconversion luminescence enhancement of $\beta-\mathrm{NaLuF}_{4}: \mathrm{Yb}^{3+} / \mathrm{Er}^{3+}, \mathrm{Er}^{3+} / \mathrm{Tm}^{3+}$ microcrystals by introducing $\mathrm{Ca}^{2+}$ for temperature sensing. CrystEngComm 2018, 20, 2029-2035. [CrossRef]

11. Sakr, H.; Tang, Z.; Furniss, D.; Sojka, L.; Sujecki, S.; Benson, T.M.; Seddon, A.B. Promising emission behavior in $\mathrm{Pr}^{3+}$ /In selenide-chalcogenide-glass small-core step index fiber (SIF). Opt. Mater. 2017, 67, 98-107. [CrossRef]

12. Wang, T.; Yu, H.; Siu, C.K.; Qiu, J.; Xu, X.; Yu, S.F. White-light whispering-gallery-mode lasing from lanthanide-doped upconversion $\mathrm{NaYF}_{4}$ hexagonal microrods. ACS Photon. 2017, 4, 1539-1543. [CrossRef]

13. Chen, Q.; Xie, X.; Huang, B.; Liang, L.; Han, S.; Yi, Z.; Wang, Y.; Li, Y.; Fan, D.; Huang, L.; et al. Confining excitation energy in $\mathrm{Er}^{3+}$-sensitized upconversion nanocrystals through $\mathrm{Tm}^{3+}$-mediated transient energy trapping. Angew. Chem. Int. Ed. Engl. 2017, 56, 7605-7609. [CrossRef] [PubMed]

14. Wu, X.; Zhang, Y.; Takle, K.; Bilsel, O.; Li, Z.; Lee, H.; Zhang, Z.; Li, D.; Fan, W.; Duan, C.; et al. Dye-sensitized core/active shell upconversion nanoparticles for optogenetics and bioimaging applications. ACS Nano 2016, 10, 1060-1066. [CrossRef] [PubMed]

15. Dong, H.; Sun, L.D.; Feng, W.; Gu, Y.; Li, F.; Yan, C.H. Versatile spectral and lifetime multiplexing nanoplatform with excitation orthogonalized upconversion luminescence. ACS Nano 2017, 11, 3289-3297. [CrossRef] [PubMed]

16. Zhuo, Z.; Liu, Y.; Liu, D.; Huang, P.; Jiang, F.; Chen, X.; Hong, M. Manipulating energy transfer in lanthanide-doped single nanoparticles for highly enhanced upconverting luminescence. Chem. Sci. 2017, 8, 5050-5056. [CrossRef]

17. Zhang, Y.; Zhang, L.; Deng, R.; Tian, J.; Zong, Y.; Jin, D.; Liu, X. Multicolor barcoding in a single upconversion crystal. J. Am. Chem. Soc. 2014, 136, 4893-4896. [CrossRef]

18. Zhang, Y.; Huang, L.; Liu, X. Unraveling epitaxial habits in the $\mathrm{NaLnF}_{4}$ system for color multiplexing at the single-particle level. Angew. Chem. Int. Ed. 2016, 55, 1-6. [CrossRef]

19. Back, M.; Marin, R.; Franceschin, M.; Sfar Hancha, N.; Enrichi, F.; Trave, E.; Polizzi, S. Energy transfer in color-tunable water-dispersible $\mathrm{Tb}-\mathrm{Eu}$ codoped $\mathrm{CaF}_{2}$ nanocrystals. J. Mater. Chem. C 2016, 4, 1906-1913. [CrossRef]

20. Lai, J.; Zhang, N.; Pasquale, N.; Lee, K. An upconversion nanoparticle with orthogonal emissions using dual NIR excitations for controlled two-way photoswitching. Angew. Chem. Int. Ed. Engl. 2014, 53, 14419-14423. [CrossRef]

21. Zhang, X.; Zhou, L.; Pang, Q.; Shi, J.; Gong, M. Tunable Luminescence and $\mathrm{Ce}^{3+} \rightarrow \mathrm{Tb}^{3+} \rightarrow \mathrm{Eu}^{3+}$ energy transfer of broadband-excited and narrow line red emitting $\mathrm{Y}_{2} \mathrm{SiO}_{5}: \mathrm{Ce}^{3+}, \mathrm{Tb}^{3+}, \mathrm{Eu}^{3+}$ phosphor. J. Phys. Chem. C 2014, 118, 7591-7598. [CrossRef]

22. Liu, J.; Rijckaert, H.; Zeng, M.; Haustraete, K.; Laforce, B.; Vincze, L.; Driessche, I.V.; Kaczmarek, A.M.; Deun, R.V. Simultaneously excited downshifting/upconversion luminescence from lanthanide-doped core/shell fluoride nanoparticles for multimode anticounterfeiting. Adv. Funct. Mater. 2018, 1707365. [CrossRef] 
23. Chen, B.; Kong, W.; Liu, Y.; Lu, Y.; Li, M.; Qiao, X.; Fan, X.; Wang, F. Crystalline hollow microrods for site-selective enhancement of nonlinear photoluminescence. Angew. Chem. Int. Ed. Engl. 2017, 56, 10383-10387. [CrossRef] [PubMed]

24. Wang, F.; Liu, X. Recent advances in the chemistry of lanthanide-doped upconversion nanocrystals. Chem. Soc. Rev. 2009, 38, 976-989. [CrossRef] [PubMed]

25. Podhorodecki, A.; Banski, M.; Misiewicz, J.; Afzaal, M.; O’Brien, P.; Chad, D.; Wang, X. Multicolor light emitters based on energy exchange between $\mathrm{Tb}$ and Eu ions co-doped into ultrasmall $\beta-\mathrm{NaYF}_{4}$ nanocrystals. J. Mater. Chem. 2012, 22, 5356. [CrossRef]

26. Kim, S.Y.; Woo, K.; Lim, K.; Lee, K.; Jang, H.S. Highly bright multicolor tunable ultrasmall $\beta-\mathrm{Na}(\mathrm{Y}, \mathrm{Gd}) \mathrm{F}_{4}: \mathrm{Ce}, \mathrm{Tb}, \mathrm{Eu} / \beta-\mathrm{NaYF}_{4}$ core/shell nanocrystals. Nanoscale 2013, 5, 9255-9263. [CrossRef] [PubMed]

27. Li, R.; Xiong, H.; Liang, Y.; Liu, Y.; Zhang, N.; Gan, S. Rapid, morphology-controllable synthesis of GdOF:Ln ${ }^{3+}$ $(\mathrm{Ln}=\mathrm{Eu}, \mathrm{Tb})$ crystals with multicolor-tunable luminescence properties. New J. Chem. 2016, 40, 1792-1798. [CrossRef]

28. Li, R.; Li, L.; Liang, Y.; Zhang, N.; Liu, Y.; Gan, S. A novel synthetic route towards monodisperse LaOF:Ln ${ }^{3+}$ $(\mathrm{Ln}=\mathrm{Eu}, \mathrm{Tb})$ hollow spheres with multicolor luminescence properties. Phys. Chem. Chem. Phys. 2015, 17, 21485-21491. [CrossRef] [PubMed]

29. Luo, Y.; Yang, R.; Zhang, X.; Hu, B.; Hu, S.; Zhou, L.; Yang, J. Shape-controllable hydrothermal synthesis of $\mathrm{NaTbF}_{4}: \mathrm{Eu}^{3+}$ microcrystals with energy transfer from $\mathrm{Tb}$ to Eu and multicolor luminescence properties. CrystEngComm 2015, 17, 7762-7771. [CrossRef]

30. Wang, F.; Liu, X. Multicolor tuning of lanthanide-doped nanoparticles by single wavelength excitation. Acc. Chem. Res. 2014, 47, 1378-1385. [CrossRef] [PubMed]

31. Chen, G.; Ågren, H.; Ohulchanskyy, T.Y.; Prasad, P.N. Light upconverting core-shell nanostructures: nanophotonic control for emerging applications. Chem. Soc. Rev. 2015, 44, 1680-1713. [CrossRef] [PubMed]

32. Ju, D.; Song, F.; Han, Y.; Cui, W.; Zhou, A.; Liu, S.; Wang, X.; Feng, M.; Ming, C. Sequential growth of uniform $\beta-\mathrm{NaYF}_{4} @ \beta-\mathrm{NaLnF}_{4}(\mathrm{Ln}=\mathrm{Y}, \mathrm{Lu}, \mathrm{Yb})$ microcrystals with luminescent properties of multicolor tuning and dual-mode emission. Nanomaterials 2017, 7, 448. [CrossRef] [PubMed]

33. Liu, X.; Deng, R.; Zhang, Y.; Wang, Y.; Chang, H.; Huang, L.; Liu, X. Probing the nature of upconversion nanocrystals: instrumentation matters. Chem. Soc. Rev. 2015, 44, 1479. [CrossRef] [PubMed]

34. Podhorodecki, A.; Banski, M.; Noculak, A.; Sojka, B.; Pawlik, G.; Misiewicz, J. On the nature of carrier relaxation and ion-ion interactions in ultrasmall $\beta-\mathrm{NaYF}_{4}: \mathrm{Eu}^{3+}$ nanocrystals effect of the surface. Nanoscale 2013, 5, 429-436. [CrossRef] [PubMed]

35. Tang, J.; Chen, L.; Li, J.; Wang, Z.; Zhang, J.; Zhang, L.; Luo, Y.; Wang, X. Selectively enhanced red upconversion luminescence and phase/size manipulation via $\mathrm{Fe}^{3+}$ doping in $\mathrm{NaYF}_{4}: \mathrm{Yb}$,Er nanocrystals. Nanoscale 2015, 7, 14752-14759. [CrossRef] [PubMed]

36. Wang, Y.; Tu, L.; Zhao, J.; Sun, Y.; Kong, X.; Zhang, H. Upconversion luminescence of $\beta-\mathrm{NaYF}_{4}: \mathrm{Yb}^{3+}, \mathrm{Er}^{3+} @ \beta-\mathrm{NaYF}_{4}$ core/shell nanoparticles: excitation power density and surface dependence. J. Phys. Chem. C 2009, 113, 7164-7169. [CrossRef]

37. Zuo, J.; Sun, D.; Tu, L.; Wu, Y.; Cao, Y.; Xue, B.; Zhang, Y.; Chang, Y.; Liu, X.; Kong, X.; et al. Precisely tailoring upconversion dynamicsvia energy migration in core-shell nanostructures. Angew. Chem. 2018, 130, 3108-3112. [CrossRef]

38. Du, S.; Wang, D.; Qiang, Q.; Ma, X.; Tang, Z.; Wang, Y. The dual-model up/down-conversion green luminescence of $\mathrm{Gd}_{6} \mathrm{O}_{5} \mathrm{~F}_{8}: \mathrm{Yb}^{3+}{ }_{,} \mathrm{Ho}^{3+}, \mathrm{Li}^{+}$and its application for temperature sensing. J. Mater. Chem. C 2016, 4, 7148-7155. [CrossRef]

(C) 2018 by the authors. Licensee MDPI, Basel, Switzerland. This article is an open access article distributed under the terms and conditions of the Creative Commons Attribution (CC BY) license (http://creativecommons.org/licenses/by/4.0/). 